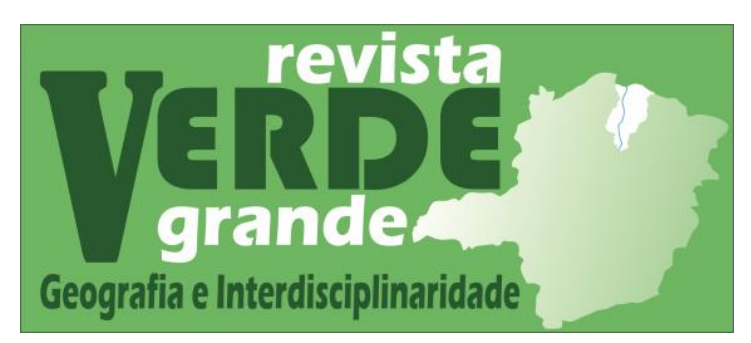

Volume 2, no. 1 (2020)

ISSN: 2675-2395

https://doi.org/10.46551.rvg2675239520201120123

\title{
CONSTRUÇÃO DE UM AQUECEDOR SOLAR E O ENSINO - APRENDIZADO DE GEOGRAFIA
}

\author{
Viviane Gonçalves Lima ${ }^{1}$ https://orcid.org/0000-0003-1639-5169 \\ Lauriane Fonseca Soares Pêgo ${ }^{2}$ https://orcid.org/0000-0001-7038-5397 \\ Maria Eugênia Félix R. Moreira ${ }^{3}$ https://orcid.org/0000-0001-9332-2874
}

\footnotetext{
${ }^{1}$ Graduanda em Licenciatura em Geografia - Universidade Estadual de Montes Claros. Bolsista PIBID/CAPES. Email: igsertao@hotmail.com

${ }^{2}$ Graduanda em Licenciatura em Geografia - Universidade Estadual de Montes Claros. Bolsista PIBID/CAPES. Email: lauriane.fonsecas@gmail.com

${ }^{3}$ Professora de Geografia - Escola Estadual Levi Peres Durães, SEE-MG. E-mail: mariaeugeniafelix@yahoo.com.br
}

\section{Resumo}

A construção do aquecedor solar foi uma atividade, do tipo oficina, desenvolvida dentro do Programa Institucional de Bolsa de Iniciação à Docência (PIBID), na Escola Estadual Levi Peres Durães, município de Montes Claros/MG. O PIBID tem o objetivo de proporcionar aos acadêmicos do curso de licenciatura em Geografia, futuros professores, a vivência da prática docente e o trabalho teórico de sala de aula, de forma participativa e interativa. A metodologia utilizada foi a apresentação de conceitos, sobre sustentabilidade, enquanto os alunos montavam o aquecedor solar com a reutilização de materiais. O resultado foi apresentado pelos alunos na Feira de Ciências, onde se tornaram instrutores dos conceitos aplicados.

Palavras-chave: Aquecedor Solar. Reutilização. Fontes de Energia. Sala de Aula

Este relato é decorrente da realização da oficina de construção de aquecedor solar com materiais reutilizáveis, durante as atividades do Programa Institucional de Bolsa de Iniciação à Docência - PIBID, desenvolvidas pela Universidade Estadual de Montes Claros (Unimontes), em parceria com a Escola Estadual Levi Peres Durães, no município de Montes Claros/MG, no sentido de proporcionar aos alunos universitários uma visão prática da licenciatura em escolas da educação básica. A oficina foi idealizada por acadêmicas bolsistas e a docente regente da educação básica, em harmonia com as habilidades do $7^{\circ}$ ano de 


\section{Construção de um aquecedor solar e o ensino - aprendizado de Geografia}

Viviane Gonçalves Lima; Lauriane Fonseca Soares Pêgo; Maria Eugênia Félix R. Moreira

Geografia, de acordo com a Base Nacional Comum Curricular (BNCC) e os principais conceitos e noções trabalhadas em sala de aula, como atividades econômicas, recursos naturais renováveis e não renováveis e fontes de energia. Foi elaborada com o objetivo de discutir com os alunos, através da construção do aquecedor solar, o tema sustentabilidade, trabalhado em sala de aula, com destaque para reutilização ${ }^{4}$ de resíduos, fontes de energias mais limpas e cidades sustentáveis, de forma prazerosa e significativa. Outro propósito foi a apresentação do aquecedor solar na feira de ciências da escola, evidenciando as estratégias de aprender e ensinar em Geografia (PONTUSCHKA, 2007).

A escolha da construção do aquecedor solar foi feita pela possibilidade de adequar o processo didático de sua construção aos temas estudados em sala de aula: baixo custo, facilidade de manuseio e a perspectiva da sua utilização para aquecimento de água na própria escola ou em casa. O projeto foi executado de forma participativa e interativa, com a apresentação do projeto ao grupo de acordo com a montagem do aquecedor, sendo que, em cada etapa, foram introduzidos os conceitos trabalhados em sala de aula, e outros relacionados à realidade da escola e dos alunos.

Para a montagem do aquecedor solar foram utilizadas garrafas pet, embalagens tetrapak, canos e conexões em PVC e baldes, materiais que podem ser encontrados em casa e em sobras de construções, coletados pelos próprios alunos. As garrafas e caixas foram medidas, cortadas e preparadas pelos alunos, (figuras 01 e 02); depois as caixas foram pintadas de preto e os canos cortados para a estrutura, (figuras 03 e 04); as estruturas do painel montadas, (figuras 05 e 06), formando uma estufa para aquecer a água que circula pelo encanamento. Ainda foram acrescentadas ao painel, dois baldes de água, um para a água fria e outro para receber a água aquecida. Dessa forma, o balde de água fria, instalado em uma altura menor, transfere para o encanamento a água que, aquecida pelo efeito estufa, expande e circula até chegar ao balde em altura maior. O aquecedor montado foi exposto na Feira de Ciências (FIGURAS 07 e 08).

A confecção do aquecedor solar envolveu não somente o grupo de alunos selecionados, mas toda a turma, através da coleta de materiais, garrafas pets, caixa tetrapak e de recursos financeiros. Contribuiu para o processo ensino aprendizagem dentro da sala de aula, proporcionando uma visão mais ampla do projeto que, além de coletivo é interdisciplinar, podendo ser trabalhado junto com as disciplinas de matemática, artes e física. A apresentação

\footnotetext{
4 Utilizamos este termo, pois os materiais usados foram reutilizados em uma nova função, dispensando reprocessamento, como em um material reciclado.
} 


\section{Construção de um aquecedor solar e o ensino - aprendizado de Geografia}

Viviane Gonçalves Lima; Lauriane Fonseca Soares Pêgo; Maria Eugênia Félix R. Moreira

do projeto, durante a Feira de Ciências (figuras 08 e 09), proporcionou o protagonismo dos alunos, que atuaram como transmissores do conhecimento e experiência adquiridos.

Figuras 1 e 2: Preparação das garrafas pets e caixas tetrapak
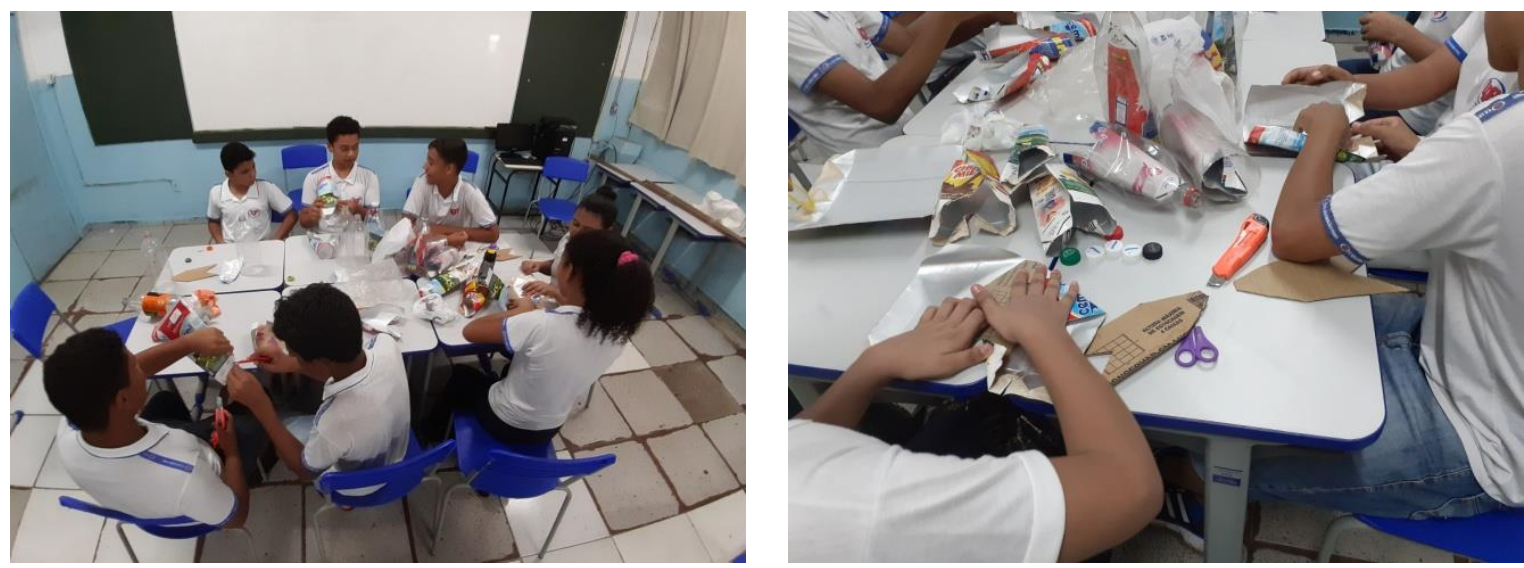

Fonte: Viviane Lima, 2019.

Figuras 3: Pintura das caixas tetrapak

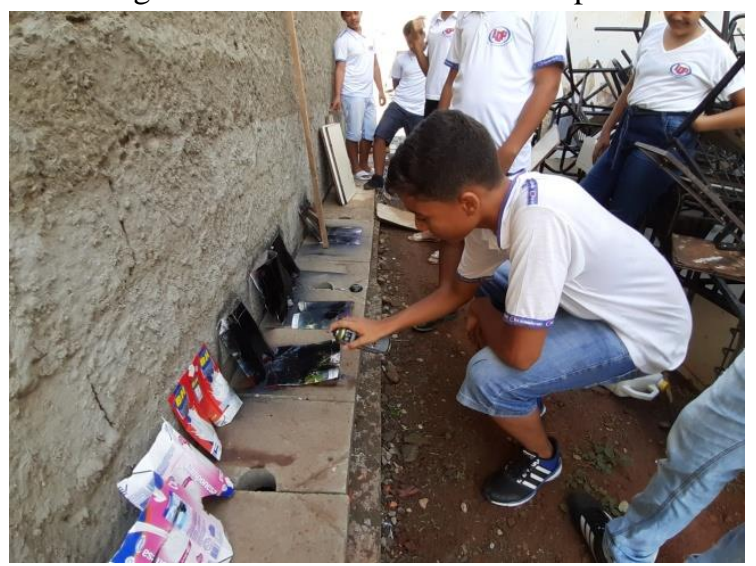

Figura 4: Montagem da estrutura do painel solar

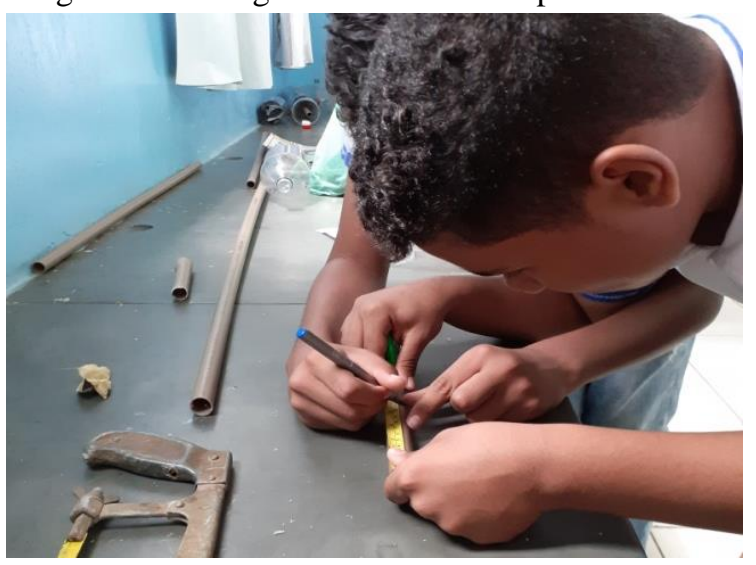

Fonte: Viviane Lima, 2019.

Figuras 5 e 6: Montagem do painel solar
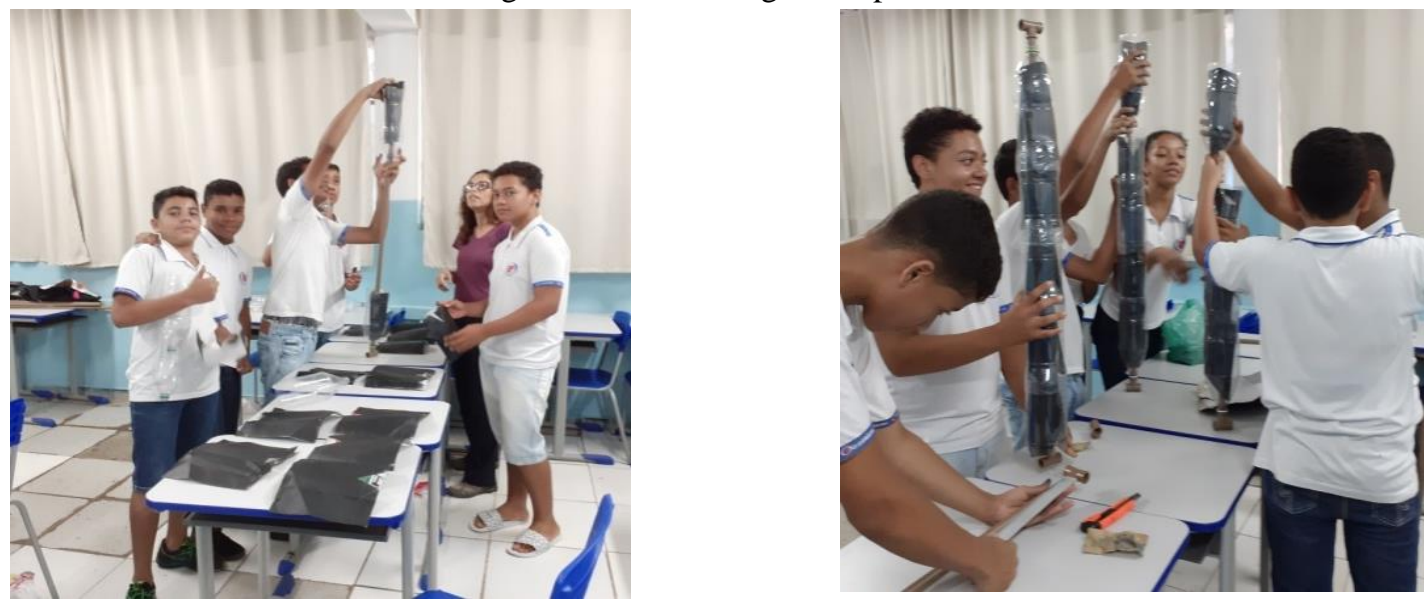

Fonte: Viviane Lima, 2019. 
Construção de um aquecedor solar e o ensino - aprendizado de Geografia

Viviane Gonçalves Lima; Lauriane Fonseca Soares Pêgo; Maria Eugênia Félix R. Moreira

Figura 1: Abertura da feira de ciências

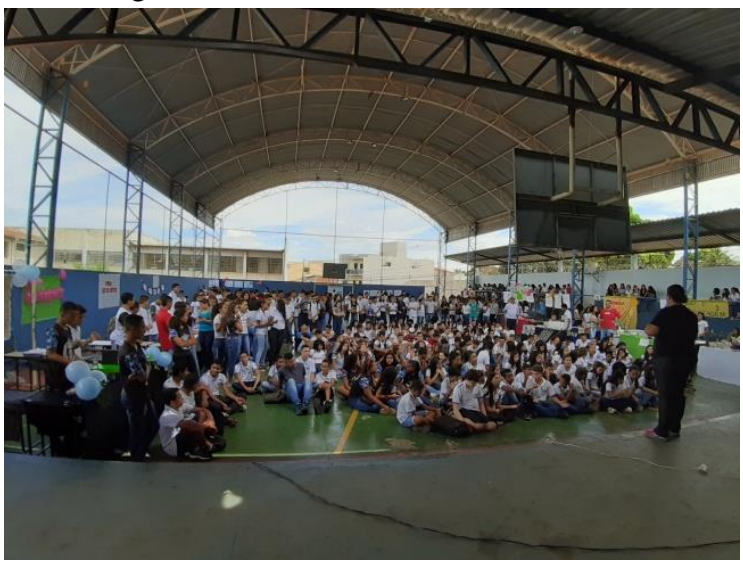

Figura 2: Apresentação do projeto durante a feira

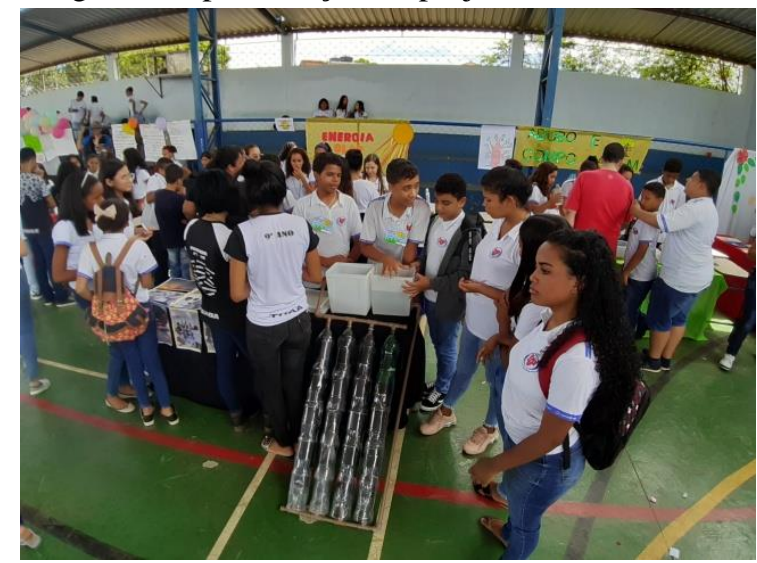

Fonte: Viviane Lima, 2019.

Figura 9: Apresentação do projeto durante a feira

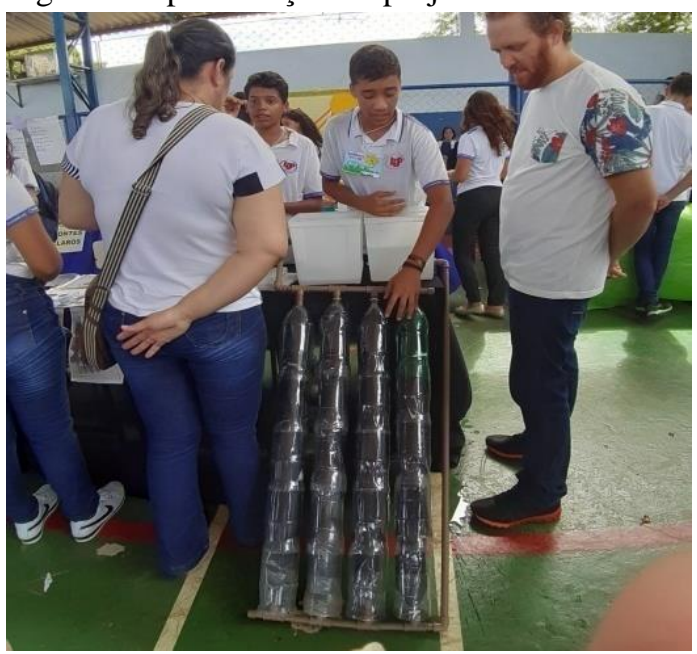

Figura 10: Equipe de montagem

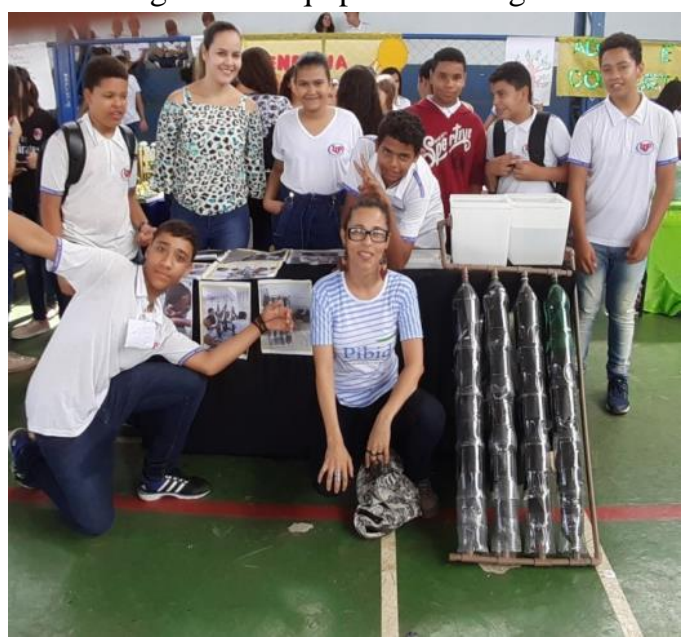

Fonte: Viviane Lima, 2019.

\section{Referências}

BRASIL. Ministério da Educação. Base Nacional Comum Curricular. Brasília, 2018. Disponível em: http://basenacionalcomum.mec.gov.br/images/BNCC_EI_EF_110518 _versaofinal_site.pdf. Acesso em: 22 dez. 2019.

PONTUSCHKA, N. N. et al. Para ensinar e aprender Geografia. São Paulo: Cortez, 2007.

\section{Agradecimentos}

Ao Programa Institucional de Bolsa de Iniciação à Docência - PIBID/CAPES.

À Escola Estadual Levi Peres Durães. 